Document downloaded from:

http://hdl.handle.net/10251/155056

This paper must be cited as:

Melgarejo-Lermas, JC.; Ossorio-García, J.; Cogollos, S.; Guglielmi, M.; Boria Esbert, VE.; Bandler, JW. (2019). On Space Mapping Techniques for Microwave Filter Tuning. IEEE Transactions on Microwave Theory and Techniques. 67(12):4860-4870. https://doi.org/10.1109/TMTT.2019.2944361

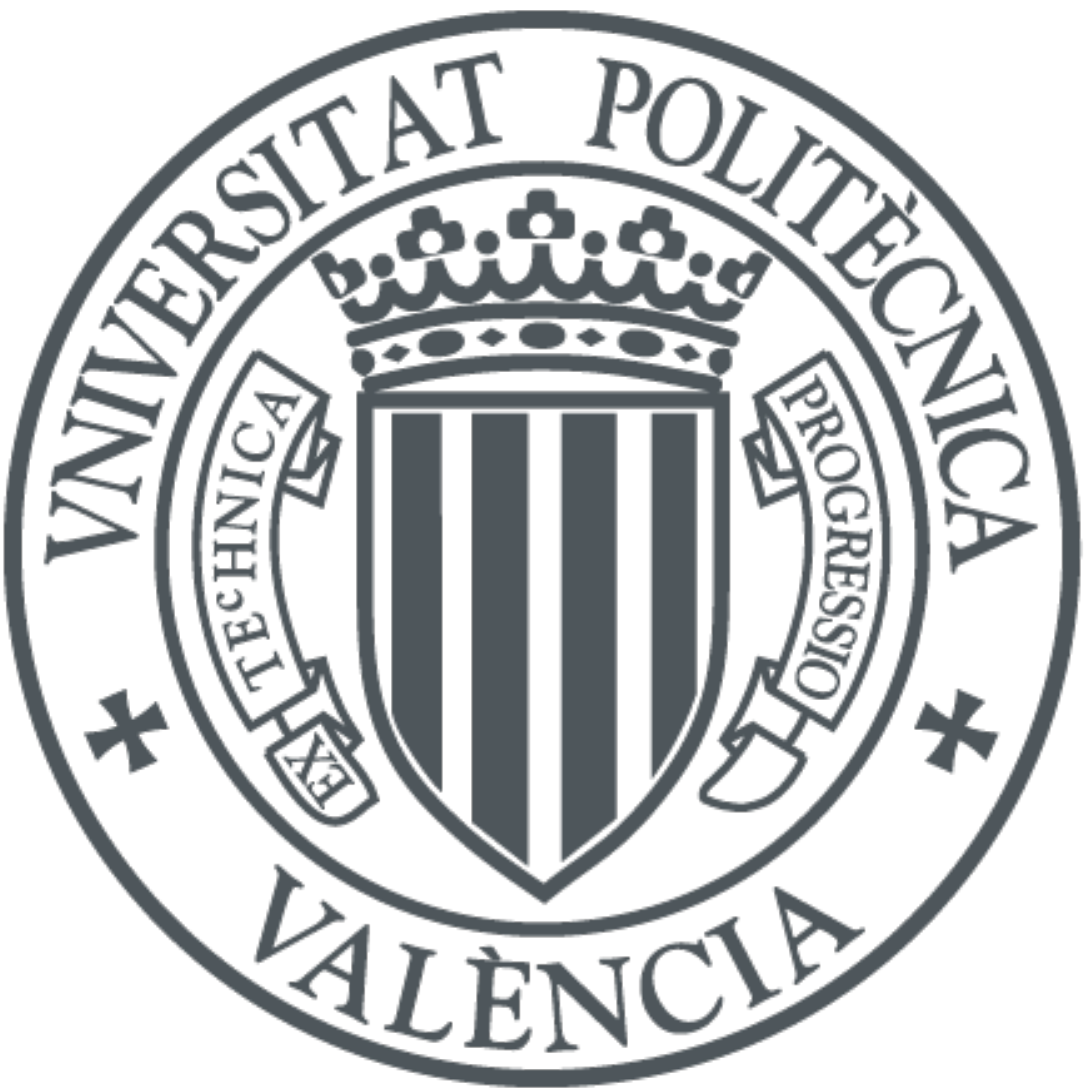

The final publication is available at

https://doi.org/10.1109/TMTT.2019.2944361

Copyright Institute of Electrical and Electronics Engineers

Additional Information 


\title{
On Space Mapping Techniques for Microwave Filter Tuning
}

\author{
Juan C. Melgarejo, Javier Ossorio, Santiago Cogollos, Member, IEEE, Marco Guglielmi, Fellow, IEEE, Vicente E. \\ Boria, Fellow, IEEE, and John W. Bandler, Life Fellow, IEEE
}

\begin{abstract}
Space Mapping (SM) and Aggressive Space Mapping (ASM) techniques are widely used in the synthesis and design of microwave filters. Their popularity stems from the inherent simplicity of the procedures and from their effectiveness. The objective of this paper is to extend the state-of-the-art of these techniques by discussing how they can also be used very effectively to tune microwave filters. In addition to theory, the successful tuning of a six-pole inductive waveguide filter is discussed in details thereby fully validating the proposed SM techniques.
\end{abstract}

Index Terms-Circuit design, microwave filter, optimization, Space Mapping (SM), tuning, waveguide filters.

\section{INTRODUCTION}

$\mathbf{G}$ ENERALLY speaking, the more accurate the manufacture of a microwave filter is, the closer to each other the measured and the simulated responses will turn out to be. However, in the practical world this comes at a cost. This is because very accurate manufacturing processes are also very expensive [1].

There are indeed specific applications where high precision manufacturing is a must. Normally, however, in the practice of the industrial production of microwave filters, low manufacturing time and cost are usually required. Tuning elements are therefore added to the basic filter structure, so that manufacturing errors can be compensated with manual tuning after manufacturing the hardware [2], [3].

The manual tuning of a microwave filter, however, can be a complex process requiring significant effort and experience [4]. It is indeed possible to find in the technical literature some guidelines on how to manually tune coupled cavity filters [5], but the tuning process generally remains a very complex

Manuscript received Month DD, YYYY; revised Month DD, YYYY; accepted Month DD, YYYY.

This work was supported by funds from "La Caixa" Foundation (Code: B004442), and from Agencia Estatal de Investigación (AEI) and Unión Europea through Fondo Europeo de Desarrollo Regional - FEDER - "Una manera de hacer Europa" (AEI/FEDER, UE), under the Research Project TEC2016-75934-C4-1-R

This paper is an expanded version from the IEEE MTT-S International Microwave Symposium (IMS 2019), Boston, MA, USA, June 2-7, 2019.

Juan C. Melgarejo, Javier Ossorio, Marco Guglielmi, Santiago Cogollos and Vicente E. Boria are with Departamento de Comunicaciones, iTEAM, Universitat Politècnica de València, E46022, Spain (e-mails: juamelle@teleco.upv.es, jaosgar@teleco.upv.es, marco.guglielmi@iteam.upv.es, sancobo@dcom.upv.es and vboria@dcom.upv.es ).

John W. Bandler is with the Department of Electrical and Computer Engineering, McMaster University, Hamilton, ON L8S 4K1, Canada, and with Bandler Corporation, Dundas, ON L9H 5E7, Canada (e-mail: bandler@mcmaster.ca). task. To improve the situation, computer-aided procedures have been extensively discussed in the technical literature. For example, one of the first computer aided approaches was discussed in [6], where a pattern search optimization was used to identify and optimize the singularity of the filter transfer function. Other contributions are [7] and [8], where the matching learning approach was explored. Fuzzy logic tuning strategies have also been used in [9], [10] for the purpose of tuning microwave filters. Many more contributions can indeed be found in the technical literature [11], [12].

One of the most effective computer aided techniques for the design of microwave filters is Space Mapping (SM). Since Bandler et al. first introduced the SM technique [13] and its further development, Aggressive Space Mapping (ASM) [14], these techniques have been widely used for the design of microwave filters [15], [16], [17], [18]. This is because SM is indeed a very powerful optimization procedure. The SM technique essentially uses two different simulation models (or spaces). A fast, low accuracy model (the coarse space), and a computationally intensive high accuracy model (the fine space). The basic idea behind SM is that most of the simulations are performed in the coarse space, while the fine space is used only for validation.

Recently, SM techniques have also been used in the tuning stage of microwave filters. In [19], ASM was used to tune a varactor-based microstrip combline filter. In [20], ASM was also used to tune a four-pole inductive waveguide filter. ASM was also used in [21] to correct the manufacturing errors in a circular-waveguide dual-mode (CWDM) filter. In that case, instead of using tuning screws, rectangular-shaped metal inserts were used, together with a few SM iterations, to obtain a compliant filter response. ASM was also used in [22] for the fast tuning of a 3D-printed lossy waveguide filter. Finally, in [23], an SM-based systematic procedure was proposed to tune waveguide filters. The idea was to establish by simulation a linear mapping between two different spaces, one related to the tuning elements penetration and the other to the physical dimensions of a reference waveguide device. The key issue demonstrated in this last contribution is that the mapping, established by simulation, is indeed maintained in the manufactured device, and that there is no need to update it during the tuning process (as opposed to what is discussed in [13]-[22]).

In this context, therefore, the aim of this paper is to extend the state-of-the-art of SM by describing how the initial results discussed in [23] can effectively be extended to become a very valid support tool for tuning microwave filters. 


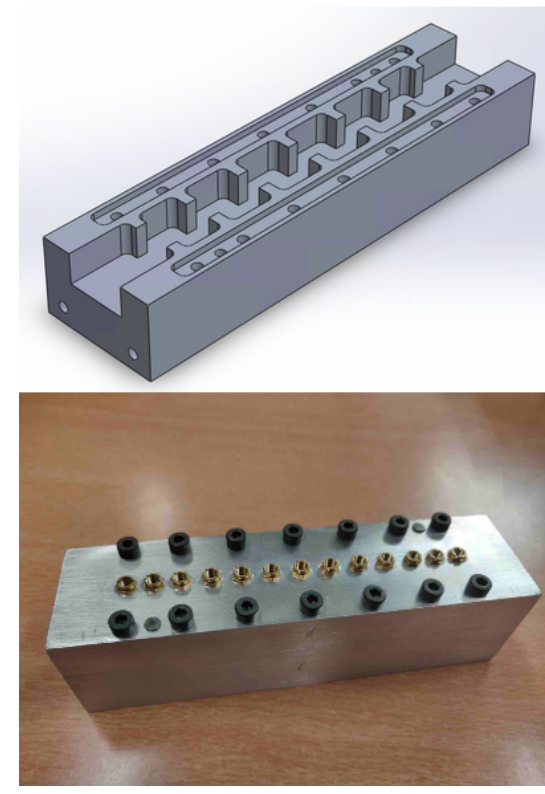

Fig. 1. Filter 1: Six-pole inductive filter with 13 tuning elements that is used as a reference in this paper.

The content of this paper is organized as follows: Section II describes the microwave filter that is used as a reference throughout the paper. Section III describes the robotic tuning setup that we developed in the framework of this work. Section IV describes the models used in the paper. Section V describes a tuning method that is used as a reference for the remainder of the paper. Section VI discusses the practical tuning of an inductive six-pole filter using the method proposed in [23]. Sections VII to IX describe the further enhancements of the basic SM procedure that are the main objective of this paper. The novel procedures are indeed shown to be very effective in accelerating the tuning process of waveguide filters. The paper is concluded with a comparative study of the results obtained, including a discussion of their relevance in a real industrial context.

\section{REFERENCE FILTER}

As a reference for all of the discussions presented in this paper, we will use an inductive filter of order six. The center frequency of the filter is $11 \mathrm{GHz}$, the bandwidth is $500 \mathrm{MHz}$. The filter uses cylindrical tuning elements ${ }^{1}$ with a radius of $1.6 \mathrm{~mm}$, and with a design depth of $2 \mathrm{~mm}$. Fig. 1 shows the assembled waveguide filter. Table I shows the dimensions of the filter. Due to geometrical symmetry, only half of the dimensions are given.

\section{A Robotic Tuning Tool: "Robby"}

To use the filter tuning algorithms discussed in this paper, it is of key importance to know with the best possible accuracy how to implement the relative changes of tuner penetrations that the tuning procedure indicates in order to tune a specific cavity or coupling. To this end, we have developed the precision robotic arm ("Robby") shown in Fig. 2. Robby is

${ }^{1}$ https://www.tronser.de
TABLE I

DIMENSIONS OF THE SIX-POLE INDUCTIVE FILTER.

\begin{tabular}{|c|c|c|}
\hline Element $^{1}$ & Dimension $^{2}$ & Screw Penetration (mm) \\
\hline Aperture 1 & 11.2951 & 2.00 \\
\hline Cavity 1 & 12.4882 & 2.00 \\
\hline Aperture 2 & 8.3848 & 2.00 \\
\hline Cavity 2 & 14.9165 & 2.00 \\
\hline Aperture 3 & 7.6944 & 2.00 \\
\hline Cavity 3 & 15.3112 & 2.00 \\
\hline Aperture 4 & 7.5829 & 2.00 \\
\hline
\end{tabular}

${ }^{1}$ The waveguide used is WR-75. All the corners have a $2 \mathrm{~mm}$ radius.

${ }^{2}$ The design variables are the lengths of the cavities and the widths of the apertures. All coupling apertures have a fixed thickness of $3.5 \mathrm{~mm}$.

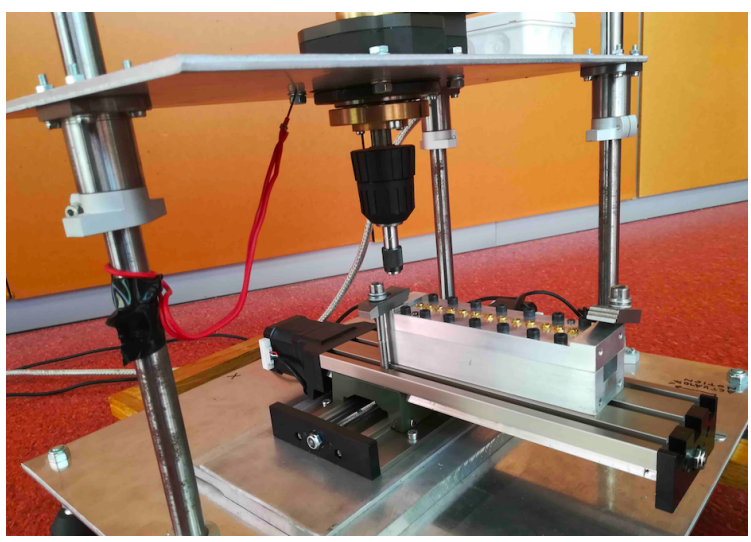

Fig. 2. Robotic tuner ("Robby") used in all tuning procedures discussed in this paper.

composed of a computer controlled $\mathrm{X}-\mathrm{Y}$ table to which the filter to be tuned is secured. Above the $\mathrm{X}-\mathrm{Y}$ table, we have placed a computer driven rotating device with an actuator that can be coupled to the tuning elements. Since the X-Y position of the tuners is known, Robby can be programmed to automatically position the actuator above the tuning elements. Coupling the actuator to the tuning elements, however, is done manually.

This mechanical system has an estimated backlash of $10^{\circ}$. As a consequence, the maximum tuning accuracy that can be achieved with this particular setup for the penetration depth of the tuning elements is about 10 microns. We estimate that this level of accuracy is indeed sufficient to successfully tune the filter shown in Fig. 1.

\section{Structures, Models And Procedures}

As mentioned in the introduction, the basic idea behind SM is to use two different spaces (or models) to design a specific filter. In the remainder of this paper, we will use a number of different filter structures and filter models to show how SM can also be used to develop tuning procedures for microwave filters. For the sake of clarity, therefore, we will first describe briefly in this section each one of the models used. Each filter structure or model will be referred to as Filter $\mathbf{N}$, where $\mathbf{N}$ is a progressive integer from 1 to 4 . 
- Filter 1: This is the actual six-pole waveguide filter that we have manufactured (see Fig 1). This filter includes rounded corners and cylindrical tuning elements. This is the breadboard that we use to demonstrate all of the tuning procedures described in the reminder of this paper. The performance of this filter is obtained by direct measurement with a Vector Network Analyzer (VNA).

- Filter 2: This filter has the same exact in-band performance of Filter $\mathbf{1}$ in the tuned state. It also uses cylindrical tuning elements but has sharp, ninety degree corners (see Fig. 4).

- Filter 3: This is the simplest filter structure that we use in this paper. The tuned in-band performance is, once again, identical to the one of Filter 1. However, this structure does not use tuning elements and has sharp ninety degree corners (see Fig. 6).

- Filter 4: This filter is identical to Filter 1, it includes round corners in all the cavities and all 13 tuning elements (see Fig. 7).

These structures have either been simulated with FEST3D from Aurorasat (now with CST and Dassault Systemes) or with Microwave Studio (from CST -Computer Simulation Technology- now with Dassault Systemes). The FEST3D analysis method is based on a multimode equivalent network (MEN) representation of waveguide junctions. Each circuit element is solved using the most appropriate method available, ensuring high-fidelity results in a relatively short time. The commercial software CST has been used with the Frequency Domain solver that is based on FEM (Finite Element Method).

Filter 2 and Filter 3 have been simulated with FEST3D because high-fidelity results can be obtained with moderate (for Filter 2) and extremely short (for Filter 3) simulation times (see Tables V and VI for details). The computation time of FEST3D for the high-fidelity results of Filter 4 is comparable to the time needed by CST, which is widely used in industry. Therefore, CST has been chosen in this case (see Table $\mathrm{V}$ for details). For all computations we have used a PC with an Intel Core i7-6700 @ $3.4 \mathrm{GHz}$ with a 12 GB RAM.

Having clearly described all of the filter structures and models that we will use in the remainder, we now show in Table II how Filters $\mathbf{1}$ to $\mathbf{4}$ are used in the context of the SM-based tuning procedures.

TABLE II

STRUCTURES AND MODELS USED FOR THE COARSE AND FINE SPACES IN EACH OF THE TECHNIQUES PROPOSED.

\begin{tabular}{|c|c|c|}
\hline Procedure & Coarse Model & Fine Model \\
\hline Procedure I & Filter 2 & Filter 1 \\
\hline Procedure II & Filter 3 & Filter 4 \\
\hline Procedure III & Filter 3 & Filter 2 \\
\hline Procedure IV & Filter 3 & Filter 2 \\
\hline Procedure V & Filter 3 & Filter 1 \\
\hline
\end{tabular}

Having now clarified the various structures and models, we discuss in the next paragraph the SM-based tuning procedures.

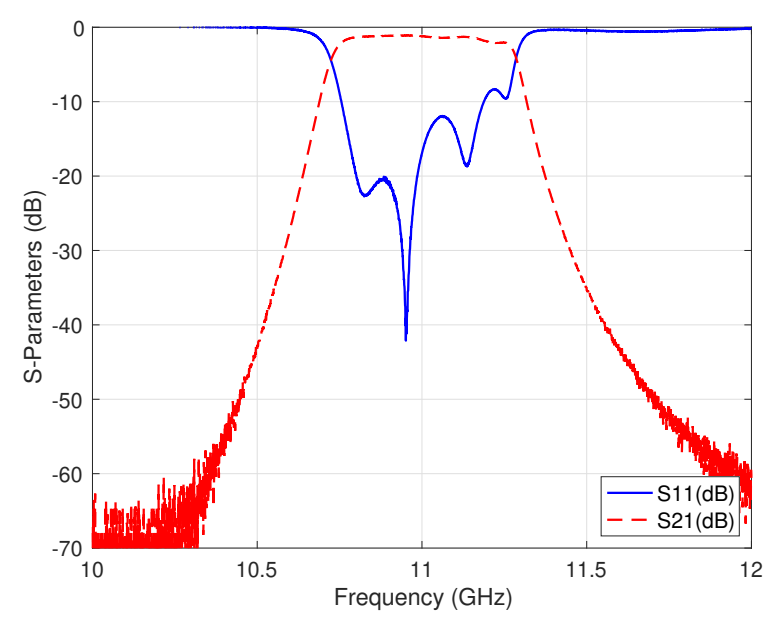

Fig. 3. Response of Filter 1 with all tuning elements set at the design depth of $2 \mathrm{~mm}$.

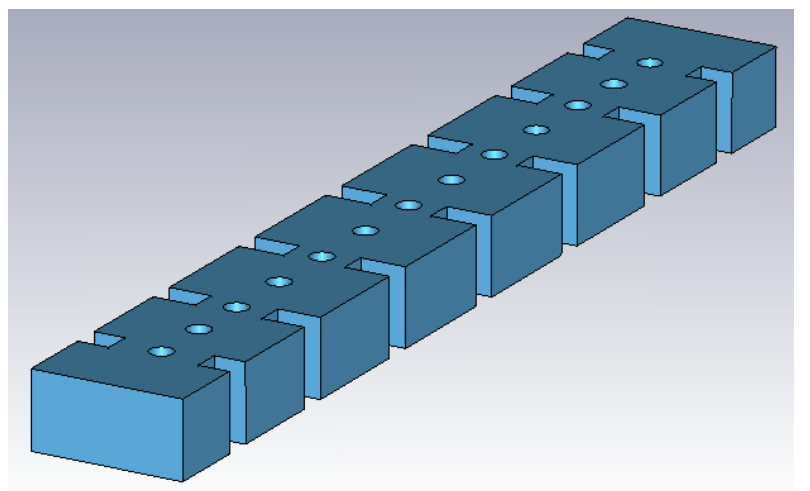

Fig. 4. Filter 2: low precision model with sharp corners and tuning screws.

\section{Procedure I: Reference Tuning}

The starting point of our tuning procedure is to set all tuning elements to the design penetration of $2.0 \mathrm{~mm}$ using Robby. The measured response obtained is shown in Fig. 3.

According to the results in [24] and [25], a first method to tune a waveguide filter can be based on the low precision model shown in Fig. 4 (Filter 2). It was, in fact, demonstrated that the Broyden matrix that relates the dimensions of the coarse model of Filter 2 with the dimensions of the manufactured filter (Filter $\mathbf{1}$ ) satisfies the relation $\mathbf{B} \approx \mathbf{I}$.

In order to tune the filter, we can use Filter $\mathbf{2}$ to recover the measured response (see Fig. 3). Using now the depths of the tuning elements in the coarse model that produce the same response as the measurements $\left(\mathbf{s c r}_{\mathbf{r}}\right)$, and the optimal tuner depth of the coarse model ( $\mathbf{s c r}_{\text {opt }}$ ), we can compute the screw displacement that we need to apply to tune the filter as follows:

$$
\Delta=-\left(\mathbf{s c r}_{\mathbf{r}}-\mathbf{s c r}_{\text {opt }}\right) .
$$

In [24] it was demonstrated that when the physical structures of the filters are identical in both spaces, the approximation $\mathbf{B} \approx \mathbf{I}$ works in fewer iterations than the well known ASM procedure based on the update of the Broyden matrix. To continue, we will therefore use the identity matrix in each iteration of the procedure. 


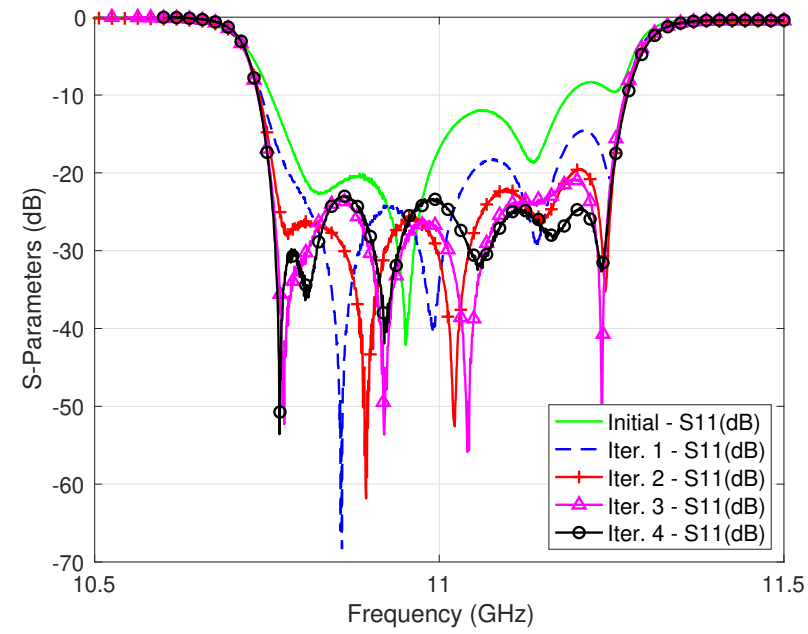

Fig. 5. Tuning procedure I using $\mathbf{B}=\mathbf{I}$

Fig. 5 shows the tuning process using the structure shown in Fig. 4 as the coarse model. The software used to simulate the coarse model was FEST3D. Four iterations are needed to successfully tune the filter. Since the starting point was relatively far away from the ideal tuned performance, the tuning method described in [24] required more than one iteration. However, even if the tuning process took only four iterations, it is important to note that the coarse model used (Fig. 4) also contains tuning elements. This means that, even though the computations in the coarse space are carried out with low accuracy, this is not a computationally efficient model. Table III shows the depths of the penetration of the screws after each iteration. Table IV shows the performance of this tuning procedure. The parameters that are considered are: the computation time of the coarse model (TC), the number of iterations needed to tune the filter $(N I)$, the average number of simulations performed by a Simplex algorithm to recover each of the measured responses $(A I)$ and the overall time needed to tune the filter (Total). In this method, Total is computed as:

$$
\text { Total }=T C \cdot A I \cdot N I
$$

The results obtained so far will be used in the subsequent sections as a reference to compare the different tuning methods for the same filter.

\section{Procedure II: Performing the Mapping With a High PRECISON EM SimUlator}

The next method we discuss is the one originally presented in [23]. We include this example in this paper to validate the results presented with the complete tuning procedure of a real waveguide filter. In this case, the coarse model is the one shown in Fig. 6 (Filter 3) and it is simulated with FEST3D. This is computationally much more efficient, since the coarse model does not include tuning elements and all cavities have sharp corners. The fine model (Filter 4) is simulated using CST. Since the filter is manufactured by milling, a radius of $2 \mathrm{~mm}$ must be introduced in each corner, as shown in Fig. 7.

The main idea presented in [23] was to compute the matrix B that describes the mapping between the widths of the irises
TABLE III

PENETRATIONS OF THE TUNING SCREWS IN EACH ITERATION OF PROCEDURE I.

\begin{tabular}{|c|c|c|c|c|}
\hline Element & Iter. 1 & Iter. 2 & Iter. 3 & Iter. 4 \\
\hline Iris 1 & 2.2549 & 2.2771 & 2.2750 & 2.2637 \\
\hline Cav. 1 & 2.0852 & 2.1527 & 2.1711 & 2.1582 \\
\hline Iris 2 & 1.9579 & 1.9710 & 1.9723 & 1.9458 \\
\hline Cav. 2 & 2.0705 & 2.1046 & 2.1144 & 2.1173 \\
\hline Iris3 & 2.0221 & 2.0698 & 2.0584 & 1.9887 \\
\hline Cav. 3 & 1.9936 & 2.0038 & 2.0086 & 2.0119 \\
\hline Iris 4 & 1.9688 & 1.9797 & 1.9636 & 1.9327 \\
\hline Cav. 4 & 1.9880 & 1.9807 & 1.9746 & 1.9715 \\
\hline Iris 5 & 2.0805 & 2.0959 & 2.0747 & 2.1022 \\
\hline Cav. 5 & 2.0097 & 2.0105 & 2.0155 & 2.0250 \\
\hline Iris 6 & 2.0275 & 2.0296 & 2.0123 & 2.2007 \\
\hline Cav. 6 & 2.1219 & 2.1611 & 2.1902 & 2.2007 \\
\hline Iris 7 & 1.9308 & 2.0119 & 2.0748 & 2.1339 \\
\hline
\end{tabular}

TABLE IV

PERFormANCE OF PROCEDURE I.

\begin{tabular}{|c|c|c|c|}
\hline$T C$ & $N I$ & $A I$ & Total \\
\hline $7.3 \mathrm{~s}$ & 4 & 762 & $6 \mathrm{~h} 10 \mathrm{~min} 50 \mathrm{~s}$ \\
\hline
\end{tabular}

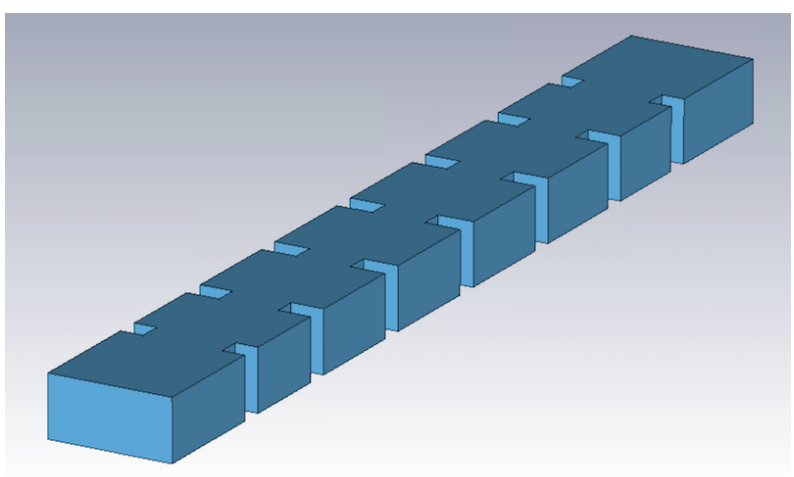

Fig. 6. Filter 3: low precision model without tuning elements.

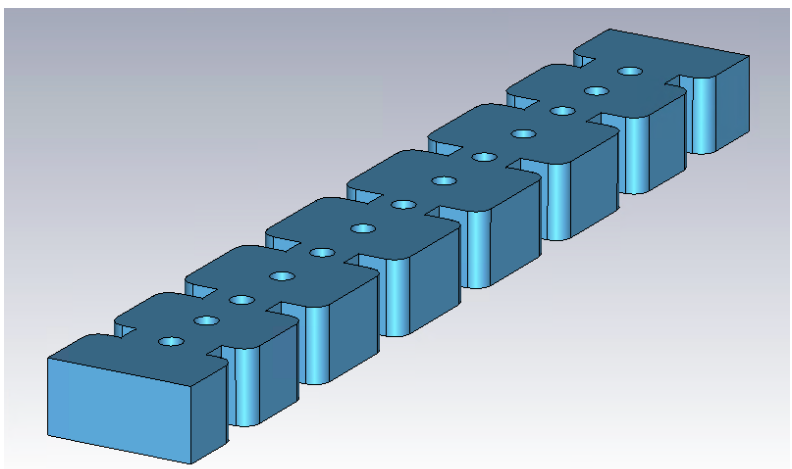

Fig. 7. Filter 4: high precision model with tuning screws and rounded corners. 
and lengths of the cavities of the low precision model in Fig. 6 (Filter 3), with the penetration of the screws in the high precision model shown in Fig. 7 (Filter 4). The resulting mapping equation is:

$$
\mathbf{x}_{\mathbf{f}}=\mathbf{B} \cdot \mathbf{x}_{\mathbf{c}}+\mathbf{C}
$$

where

1) $\mathbf{x}_{\mathbf{f}}$ is an $N \times 1$ vector that contains the penetration of the tuning elements of the fine model.

2) $\mathbf{R}_{\mathbf{f}}\left(\mathbf{x}_{\mathbf{f}}\right)$ is the response of the fine model.

3) $\mathbf{x}_{\mathbf{c}}$ is an $N \times 1$ vector that contains the dimensions of the cavities and irises of the low precision model.

4) $\mathbf{R}_{\mathbf{c}}\left(\mathbf{x}_{\mathbf{c}}\right)$ is the response of the coarse model.

so that we can write:

$$
\mathbf{R}_{\mathbf{c}}\left(\mathbf{x}_{\mathbf{c}}\right)=\mathbf{R}_{\mathbf{f}}\left(\mathbf{x}_{\mathbf{f}}\right)
$$

The optimum dimensions in the fine and coarse space are, respectively, $\mathbf{x}_{\mathbf{f} \text { opt }}$ and $\mathbf{x}_{\mathbf{c o p t}}$. It is important to note that both vectors have already been computed during the design process. They provide, in fact, the tuned response of the filter, namely:

$$
\mathbf{R}_{\mathbf{f}}\left(\mathbf{x}_{\mathbf{f o p t}}\right)=\mathbf{R}_{\mathbf{c}}\left(\mathbf{x}_{\mathbf{c o p t}}\right)
$$

In order to obtain the matrix $\mathbf{B}$ that links the two spaces, we will slightly modify the penetration of one of the tuning screws in the fine model, $\mathbf{x}_{\mathbf{f} 1}$, and through optimization with the coarse model, we then find the vector $\mathbf{x}_{\mathbf{c} 1}$ so that:

$$
\mathbf{R}_{\mathbf{c}}\left(\mathbf{x}_{\mathbf{c} 1}\right)=\mathbf{R}_{\mathbf{f}}\left(\mathbf{x}_{\mathbf{f} \mathbf{1}}\right) .
$$

Subtracting (8) and (7) we obtain (9)

$$
\begin{aligned}
\mathbf{x}_{\mathbf{f o p t}} & =\mathbf{B} \cdot \mathbf{x}_{\mathbf{c o p t}}+\mathbf{C} \\
\mathbf{x}_{\mathbf{f} 1} & =\mathbf{B} \cdot \mathbf{x}_{\mathbf{c} 1}+\mathbf{C} \\
\mathbf{x}_{\mathbf{f ~ o p t}}-\mathbf{x}_{\mathbf{f} 1} & =\mathbf{B} \cdot\left(\mathbf{x}_{\mathbf{c o p t}}-\mathbf{x}_{\mathbf{c} \mathbf{1}}\right)
\end{aligned}
$$

The expression (9) can be written as:

$$
\Delta \mathbf{x}_{\mathbf{f} 1}=\mathbf{B} \cdot \Delta \mathbf{x}_{\mathbf{c} 1}
$$

which in explicit form becomes

$$
\begin{aligned}
\Delta x_{f_{11}} & =B_{11} \Delta x_{c 11}+\cdots+B_{1 N} \Delta x_{c 1 N} \\
\vdots & \\
\Delta x_{f_{1 N}} & =B_{N 1} \Delta x_{c 11}+\cdots+B_{N N} \Delta x_{c 1 N}
\end{aligned}
$$

In this case, we have a system of $N$ equations with $N^{2}$ unknowns: the entries of $\mathbf{B}$. In order to solve the system, it is necessary to add $N-1$ additional matrix equations. The complete system becomes:

$$
\begin{aligned}
\Delta \mathbf{x}_{\mathbf{f} 1} & =\mathrm{B} \cdot \Delta \mathbf{x}_{\mathbf{c} 1} \\
\vdots & \\
\Delta \mathbf{x}_{\mathbf{f} \mathbf{N}} & =\mathrm{B} \cdot \Delta \mathbf{x}_{\mathbf{c N}}
\end{aligned}
$$

The needed mapping points are obtained by changing the penetration of each tuning element, one at the time, by 0.1 $\mathrm{mm}$ from the original design depth.

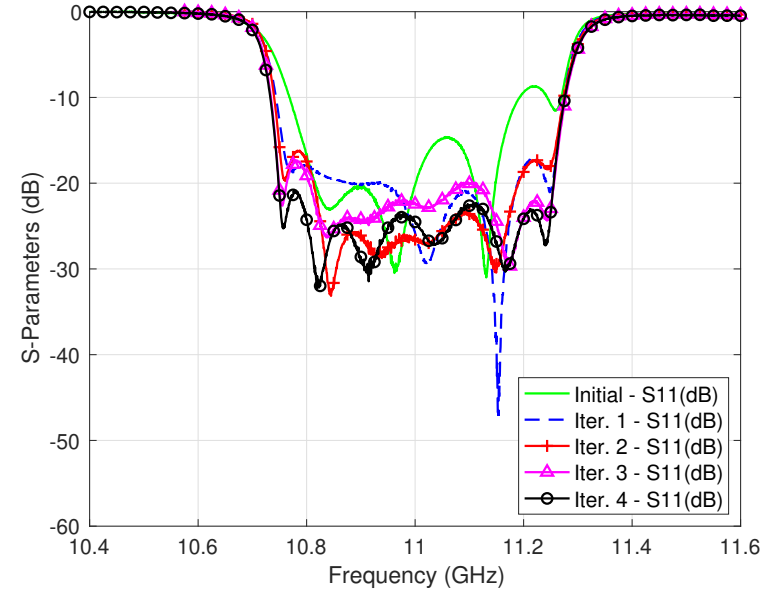

Fig. 8. Tuning procedure II using matrix $\mathbf{B}$ calculated with the high precision EM simulator (CST).

Once all the equations have been obtained, the system can be solved, and the mapping matrix $\mathbf{B}$ can be computed. In this case, due to geometrical symmetry in the filter, it is necessary to map the variation of only half of the tuners. Naturally, when the filter is manufactured, the real dimensions will vary from the nominal ones. However, in [23] it was shown that the relationship between the depth of penetration of the real tuning elements in the correctly tuned state and the parameters of the ideal filter in the coarse space is (essentially) the same. To apply the tuning procedure, we then first measure the filter response with a VNA to obtain the detuned response $\mathbf{R}_{\mathbf{m}}\left(\mathbf{x}_{\mathbf{m}}\right)$. The next step is to find the values of $\mathbf{x}_{\mathbf{c} \mathbf{m}}$ such that

$$
\mathbf{R}_{\mathbf{c}}\left(\mathbf{x}_{\mathbf{c m}}\right)=\mathbf{R}_{\mathbf{m}}\left(\mathbf{x}_{\mathbf{m}}\right)
$$

After the detuned response has been recovered using the coarse model $\left(\mathbf{x}_{\mathbf{c m}}\right)$, the optimal position of the tuning elements of the physical device, $\mathbf{x}_{\mathbf{m o p t}}$, is directly given by:

$$
\mathbf{x}_{\mathbf{m o p t}}=\mathbf{x}_{\mathbf{m}}+\mathbf{B} \cdot\left(\mathbf{x}_{\mathbf{c o p t}}-\mathbf{x}_{\mathbf{c m}}\right)
$$

The last part of (14) gives the corrections to include in the tuning elements using Robby:

$$
\Delta=\mathrm{B} \cdot\left(\mathrm{x}_{\mathbf{c o p t}}-\mathrm{x}_{\mathbf{c m}}\right)
$$

Fig. 8 shows the tuning process using this mapping. It takes the same amount of iterations as the reference method (section V) to perfectly tune the filter. However, the coarse model used in this case (Fig. 6) is considerably faster. This method is therefore the best of the two options.

Table $\mathrm{V}$ shows the performance of this procedure. Three extra parameters are considered in this case: the computation time of the fine model ( $T F$ ), the average number of simulations performed by a gradient-based algorithm to recover each one of the disturbances $(A D)$ and the overall time required to estimate the Broyden matrix $(T B)$. The overall time necessary to tune the filter is given by Total:

$$
\text { Total }=T B+T C \cdot A I \cdot N I,
$$

where $T B$ is computed as

$$
T B=(T F+A D \cdot T C) \cdot N,
$$


TABLE V

PERFormance of PROCEDURE II

\begin{tabular}{|c|c|c|c|c|c|c|}
\hline$T C$ & $T F$ & $A D$ & $T B$ & $N I$ & $A I$ & Total \\
\hline $0.147 \mathrm{~s}$ & $420 \mathrm{~s}$ & 245 & $53 \min 12 \mathrm{~s}$ & 4 & 703 & $1 \mathrm{~h} 5 \mathrm{~s}$ \\
\hline
\end{tabular}

and where $N$ is the number of disturbances necessary to compute B. In this case, due to geometrical symmetry, $N=7$.

Although the tuning is carried out very quickly, the process of obtaining $\mathbf{B}$ just described can be rather time consuming. Note that the time needed to compute $\mathbf{B}(T B)$ is $88.54 \%$ of the overall time needed to tune the filter. This is because we need to perform as many simulations with the fine structure of Fig. 7 as there are tuning elements. Naturally, as the order of the filter increases, the number of simulations that must be performed in the high precision simulator increases. In sections VII to IX this limitation will be removed by introducing several enhancements in the mapping procedure.

\section{Procedure III: Performing the Mapping With a LOW PRECISON SiMULATOR}

In [24] and [25] it was shown that the Broyden matrix that relates the dimensions $\mathbf{x}_{\mathbf{c}}$ of the coarse model of Fig. 4 with the dimensions of the high precision model of the structure shown in Fig. $7\left(\mathbf{x}_{\mathbf{f}}\right)$ satisfies the condition that $\mathbf{B} \approx \mathbf{I}$. As a consequence, we can write

$$
\begin{aligned}
& \mathbf{x}_{\mathbf{f}}=\mathbf{B} \cdot \mathbf{x}_{\mathbf{c}}+\mathbf{C} \\
& \mathbf{x}_{\mathbf{f}} \approx \mathbf{x}_{\mathbf{c}}+\mathbf{C} .
\end{aligned}
$$

It is important to note that this is true regardless of what the vectors $\mathbf{x}_{\mathbf{f}}$ and $\mathbf{x}_{\mathbf{c}}$ represent. Whether both vectors contain the widths of the irises and the lengths of the cavities, or if both vectors contain the depths of penetration of the tuning elements, the matrix $\mathbf{B}$ that relates the coarse and fine space can always be approximated by the identity $\mathbf{I}$.

Redefining $\mathbf{x}_{\mathbf{c}}$ as $\mathbf{x}_{\mathbf{f} \mathbf{L P}}$, the expression (19) becomes:

$$
\mathrm{x}_{\mathrm{f}} \approx \mathrm{x}_{\mathrm{fLP}}+\mathrm{C}_{\mathbf{1}}
$$

where $\mathbf{x}_{\mathbf{f}}$ represents the depth of the tuning elements of the high precision structure with rounded corners in Fig. 7, and $\mathbf{x}_{\mathbf{f} L \mathbf{P}}$ represents the depth of penetration of the tuning elements of the low precision structure with sharp corners shown in Fig. 4. Combining (20) and (3), we can then establish that:

$$
\mathrm{x}_{\mathrm{fLP}}+\mathrm{C}_{1} \approx \mathrm{B} \cdot \mathrm{x}_{\mathrm{c}}+\mathrm{C}
$$

Rearranging the terms and renaming the constants, we finally obtain:

$$
\mathrm{x}_{\mathrm{fLP}} \approx \mathrm{B} \cdot \mathrm{x}_{\mathrm{c}}+\mathrm{C}_{2}
$$

This result is very interesting since it means that it is not necessary to establish the mapping with a high precision simulation like the one of Fig. 7 (Filter 4). It is, in fact, possible to use a low precision structure with tuning elements like the one shown in Fig. 4 (Filter 2).

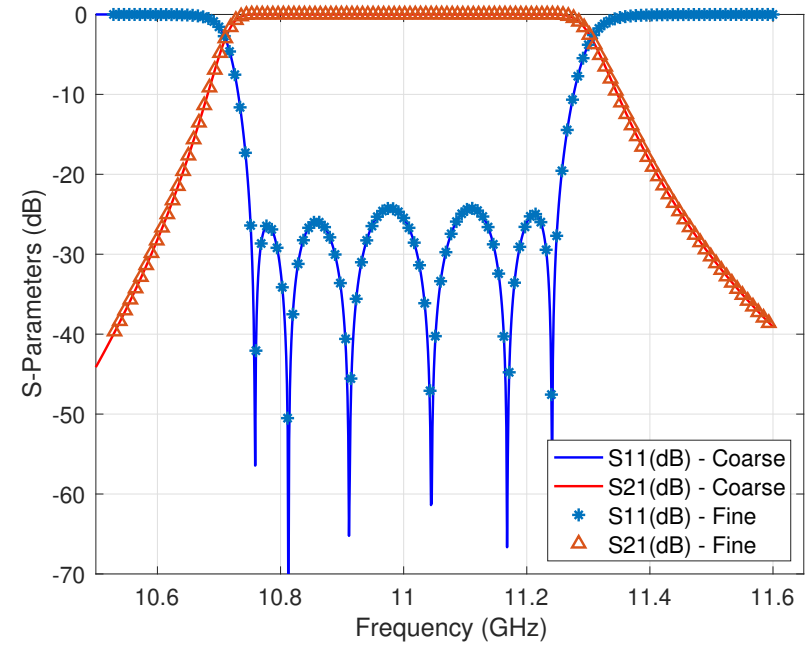

Fig. 9. Aligned responses of Filter 2 and Filter 4.

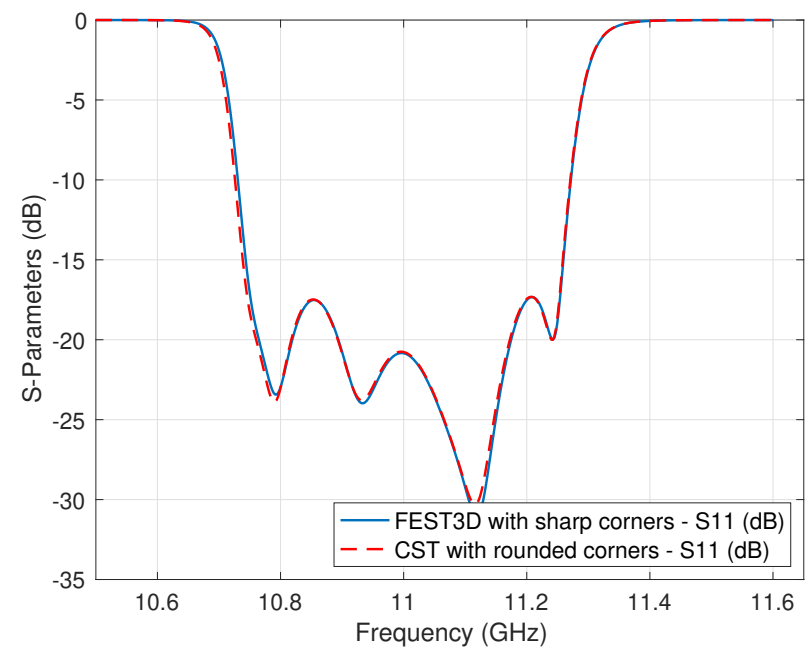

Fig. 10. Filters 2 and 4: disturbance of the second cavity. Depth of the tuning element: $2.05 \mathrm{~mm}$.

\section{A. Validating the Hypothesis}

In order to verify what was stated in (22), the best test consists of aligning the responses of Filter $\mathbf{4}$ and Filter 2, as shown in Fig. 9, and then modifying their tuning elements of the same amount, and comparing the results.

Fig. 10 shows the result of modifying the tuning element of the second cavity by $0.05 \mathrm{~mm}$ from the design depth of 2 $\mathrm{mm}$ in both spaces.

The results obtained indicate that, for small perturbations $(0.05 \mathrm{~mm})$, both simulators give practically identical responses. However, we must not forget that, as we increase the level of the disturbances, the differences between the simulators will increase. Fig. 11 shows the results of modifying the same tuning element from $2 \mathrm{~mm}$ to $2.1 \mathrm{~mm}$.

The previous results confirm that, as expected, it is not necessary to use a high precision simulation (Filter 4) to perform the mapping. Instead, it is possible to use the low precision structure that includes tuning elements like the one shown in Fig. 4 (Filter 2). 


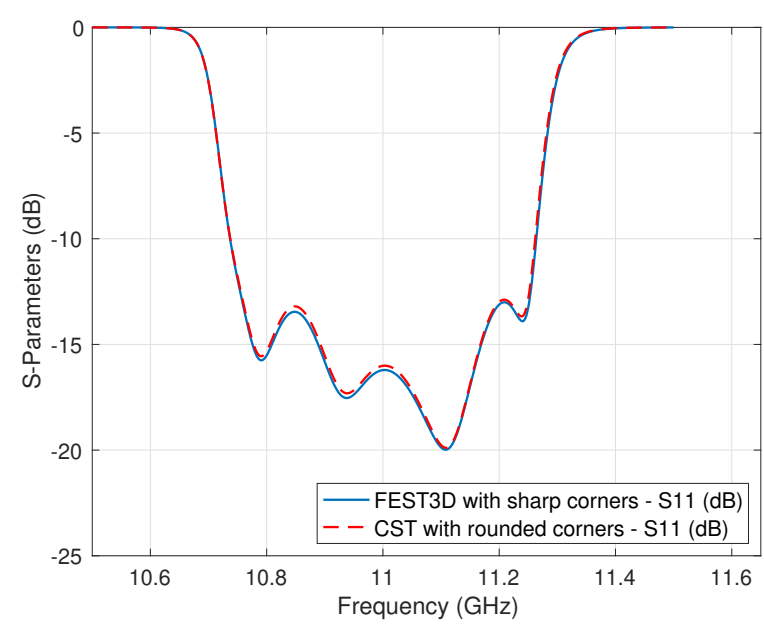

Fig. 11. Filters 2 and 4: disturbance of the second cavity. Depth of the tuning element: $2.1 \mathrm{~mm}$.

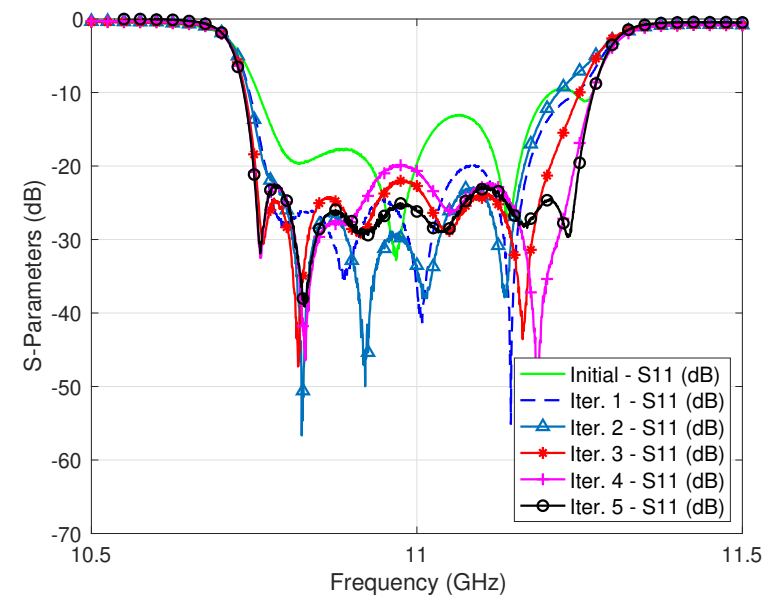

Fig. 12. Tuning procedure III using the mapping $\mathbf{B}$ computed with the low precision simulator (FEST3D).

\section{B. Tuning of the Filter}

The mapping between the penetration of the tuning elements $\mathbf{x}_{\mathbf{f}}$ in the structure simulated with low accuracy with FEST3D (Filter 2), and the widths of the irises and the lengths of the cavities $\mathbf{x}_{\mathbf{c}}$ for the structure shown in Figure 6 (Filter $\mathbf{3}$ ), is obtained by applying the procedure described in equations (3) - (12).

It is now important to remember that, during the optimization process with the coarse model to recover each disturbance, all the parameters of the structure have been optimized simultaneously. Fig. 12 shows the tuning process using the matrix $\mathbf{B}$ computed with the low precision structure shown in Fig. 4.

Five iterations are necessary to correctly tune the filter. In this case, however, the mapping matrix $\mathbf{B}$ is obtained more efficiently by using FEST3D as the fine model with the structure in Fig. 4. This approach is therefore more efficient than the original method discussed in section VI. Table VI shows the performance of this method using the same metrics as in the previous procedure. In this case, the overall time necessary to tune the filter (Total) is computed using (16).
TABLE VI

PERFORMANCE OF PROCEDURE III.

\begin{tabular}{|c|c|c|c|c|c|c|}
\hline$T C$ & $T F$ & $A D$ & $T B$ & $N I$ & $A I$ & Total \\
\hline $0.147 \mathrm{~s}$ & $7.3 \mathrm{~s}$ & 271 & $5 \min 29 \mathrm{~s}$ & 5 & 659 & $13 \min 34 \mathrm{~s}$ \\
\hline
\end{tabular}

TABLE VII

PROCEDURE III: HALF MATRIX B WHEN PERFORMING THE OPTIMIZATION ON ALL PARAMETERS.

$\left(\begin{array}{ccccccc}\mathbf{0 . 9 4 5} & \mathbf{0 . 1 7 9} & 0.059 & 0.026 & -0.001 & 0.014 & 0.010 \\ \mathbf{0 . 0 2 8} & \mathbf{0 . 5 2 4} & \mathbf{0 . 1 7 3} & -0.006 & 0.008 & -0.002 & 0.011 \\ -0.005 & \mathbf{0 . 0 0 1} & \mathbf{1 . 8 5 0} & \mathbf{0 . 0 2 4} & 0.021 & 0.028 & -0.017 \\ -0.008 & 0.007 & \mathbf{0 . 1 3 9} & \mathbf{0 . 5 3 7} & \mathbf{0 . 1 4 7} & 0 & 0 \\ -0.032 & 0.082 & 0.029 & \mathbf{- 0 . 0 6 9} & \mathbf{2 . 1 2 2} & -\mathbf{0 . 0 5 4} & 0.009 \\ 0.003 & 0 & 0.001 & 0.0103 & \mathbf{0 . 1 4 2} & \mathbf{0 . 5 3 2} & \mathbf{0 . 1 5 0} \\ 0.004 & 0.013 & 0.006 & 0.030 & 0.007 & -\mathbf{0 . 0 8 0} & \mathbf{2 . 1 7 7} \\ 0.002 & -0.002 & 0.002 & 0.002 & 0.002 & 0.006 & \mathbf{0 . 1 3 8} \\ 0.002 & -0.017 & -0.003 & 0.013 & -0.014 & 0.002 & 0.004 \\ 0 & -0.005 & 0 & 0.002 & 0.004 & -0.001 & -0.001 \\ 0.025 & 0 & 0.012 & -0.007 & -0.021 & 0.024 & 0.021 \\ 0.004 & -0.012 & 0.001 & 0.004 & 0.012 & -0.002 & 0.004 \\ 0.019 & 0.006 & 0.014 & -0.002 & -0.005 & 0.0135 & 0.001\end{array}\right)$

The speedup is achieved because the computation time of the fine model $(T F)$ is reduced, and so, the time needed to estimate the $\mathbf{B}$ matrix $(T B)$ is greatly reduced. Even though this procedure took $N I=5$ iterations to converge, the same result was obtained 4.42 times faster than with Procedure II.

\section{Procedure IV: Performing the Mapping with A Low PRECison Simulator in a Reduced OPTIMIZATION SPACE}

As mentioned in the previous sections, the main effort in applying all the techniques discussed so far is related to the cost of computing the mapping itself $(T B)$. The coarse simulator has to recover each of the $N$ perturbations of the fine model in order to compute B. Ideally, to accurately recover the objective response, we should perform an optimization using all the parameters of the coarse model until a set $\mathbf{x}_{\mathbf{c}}$ is found such that $\mathbf{R}_{\mathbf{c}}\left(\mathbf{x}_{\mathbf{c}}\right)=\mathbf{R}_{\mathbf{f}}\left(\mathbf{x}_{\mathbf{f}}\right)$.

TABLE VIII

PROCEDURE IV: HALF OF MATRIX B WHEN PERFORMING A THREE PARAMETERS OPTIMIZATION

$\left(\begin{array}{ccccccc}\mathbf{0 . 9 3} & \mathbf{0} & 0 & 0 & 0 & 0 & 0 \\ \mathbf{0 . 0 5} & \mathbf{0 . 5 5} & \mathbf{0 . 1 8} & 0 & 0 & 0 & 0 \\ 0 & \mathbf{0} & \mathbf{1 . 8 6} & \mathbf{0} & 0 & 0 & 0 \\ 0 & 0 & \mathbf{0 . 1 4} & \mathbf{0 . 5 3} & \mathbf{0 . 1 4} & 0 & 0 \\ 0 & 0 & 0 & \mathbf{0} & \mathbf{2 . 1 1} & -\mathbf{0 . 0 5} & -0.01 \\ 0 & 0 & 0 & 0 & \mathbf{0 . 1 4} & \mathbf{0 . 5 3} & \mathbf{0 . 1 5} \\ 0 & 0 & 0 & 0 & -0.01 & -\mathbf{0 . 0 4} & \mathbf{2 . 1 9} \\ 0 & 0 & 0 & 0 & 0 & 0 & \mathbf{0 . 1 3} \\ 0 & 0 & 0 & 0 & 0 & 0 & 0.01 \\ 0 & 0 & 0 & 0 & 0 & 0 & 0 \\ 0 & 0 & 0 & 0 & 0 & 0 & 0 \\ 0 & 0 & 0 & 0 & 0 & 0 & 0 \\ 0 & 0 & 0 & 0 & 0 & 0 & 0\end{array}\right)$




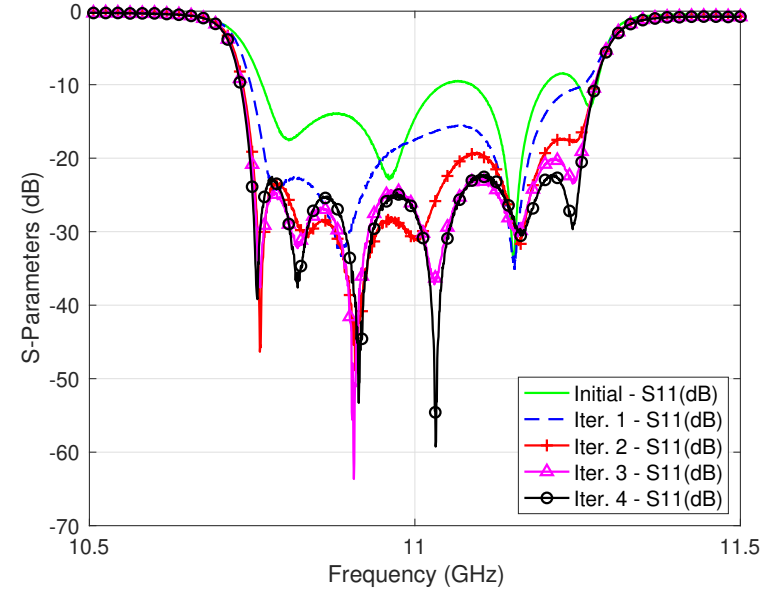

Fig. 13. Tuning procedure IV using the mapping $\mathbf{B}$ computed with low precision simulator (FEST3D) and with a reduced optimization space.

The problem is that as the order of the filter increases, so does the optimization space that we must work with. As we increase the size of the optimization space, obtaining $\mathbf{B}$ becomes progressively more time consuming because the average number of simulations to recover each disturbance $(A D)$ increases. However, when recovering the disturbance of a tuning element, the elements of the coarse model that are most affected are the iris or the cavity corresponding to the element that has been disturbed, and the two adjacent ones. We can, therefore, reduce the optimization space to only three variables, thus significantly reducing the computational time to obtain $\mathbf{B}$.

Tables VII and VIII show the matrix resulting from working with the entire optimization space or the one obtained with the space reduced to only three variables, respectively. Due to geometrical symmetry in the original filter, only a half of each matrix is shown. The values lower than 0.001 have been rounded to 0 . As we can see, the values of the main and of the two adjacent diagonals are indeed very similar. Fig. 13 shows the tuning process when using the reduced $\mathbf{B}$ shown in Table VIII.

Four iterations are enough to tune the device almost perfectly. This approach is therefore the best choice to efficiently tune the filter (see Table IX for its performance ). In summary:

1) In this case, the fine model used to calculate the mapping is a low precision model (Filter 2). The $N$ disturbances necessary to compute $\mathbf{B}$ can be simulated in seconds.

2) Furthermore, since the optimization space for the mapping has been reduced to only three variables, each of the $N$ disturbances can be recovered with the coarse model (Filter 3) very efficiently.

3) The results shown in Fig. 13 clearly indicate that the reduced mapping works just as well as the complete mapping that we have used in previous cases.

\section{PRocedure V: DiRECT MAPPING}

When tuning a filter in an industrial environment, it may happen that the person actually tuning the filter does not have
TABLE IX

PERFormancE OF PROCEDURE IV.

\begin{tabular}{|c|c|c|c|c|c|c|}
\hline$T C$ & $T F$ & $A D$ & $T B$ & $N I$ & $A I$ & Total \\
\hline $0.147 \mathrm{~s}$ & $7.3 \mathrm{~s}$ & 76 & $2 \min 9 \mathrm{~s}$ & 4 & 483 & 8 min $52 \mathrm{~s}$ \\
\hline
\end{tabular}

TABLE X

PERFORMANCE OF PROCEDURE V.

\begin{tabular}{|c|c|c|c|c|c|c|}
\hline$T C$ & $T F$ & $A D$ & $T B$ & $N I$ & $A I$ & Total \\
\hline $0.147 \mathrm{~s}$ & 0 & 67 & $1 \mathrm{~min} 9 \mathrm{~s}$ & 3 & 604 & 5 min 35 s \\
\hline
\end{tabular}

at their disposal any of the sophisticated EM simulation tools used so far in this paper.

In this case, the simplest way to proceed is to recover the response measured with the VNA, $\left(\mathbf{x}_{\mathbf{f}}\right)$, using any coarse simulator, $\left(\mathbf{x}_{\mathbf{c}}\right)$. Using, for instance, Filter $\mathbf{3}$ as a coarse model, and the real filter as the fine model.

At this point, it is important to recall that the $\mathbf{B}$ matrix establishes a linear mapping between the parameters of the fine and coarse models. In the procedures described in sections VI-VIII (Procedures II-IV), an EM full-wave simulator was used to estimate the matrix B around the optimal (tuned) performance. We are now assuming that no EM tools are available, and so, there are two ways we could proceed:

1) We could perform the estimation of the $\mathbf{B}$ matrix around the initial measured response. However, that estimation would not be valid around the tuned response and the method would have a very poor convergence. In that case, the mapping matrix should be estimated again or updated via an ASM approach.

2) Another alternative would be to manually find a slightly better initial state using the method described in [5], and estimate $\mathbf{B}$ around that improved initial state.

Since option one has already been implemented in [19], [21] and [22] and since, in some cases, an initial manual adjustment is indeed feasible, we decided to continue with option two.

The mapping can then be simply computed by perturbing directly the hardware being measured (that is Filter 1).

Fig. 14 shows the recovery of the improved response measured with the VNA. From this point, we simply slightly modify one of the tuning elements using Robby. Next, we recover the disturbed response in the coarse space. From this point, we use Robby again to set the modified tuning element back to its original position. This process is repeated for the $N$ tuning elements. In this case, the reduced matrix approach of section VIII has also been used.

After mapping the spaces, the procedure described in section VI is used to calculate the displacement of the tuning elements of the real structure. These displacements are again applied with Robby. Fig. 15 shows that an almost perfectly tuned result has been obtained with just 3 iterations. Table $\mathrm{X}$ shows the metrics of this method. We assume that the measure is instantaneous, and so, the computation time of the fine model is $T F=0$. In this case, the value of Total is computed as in (16). 


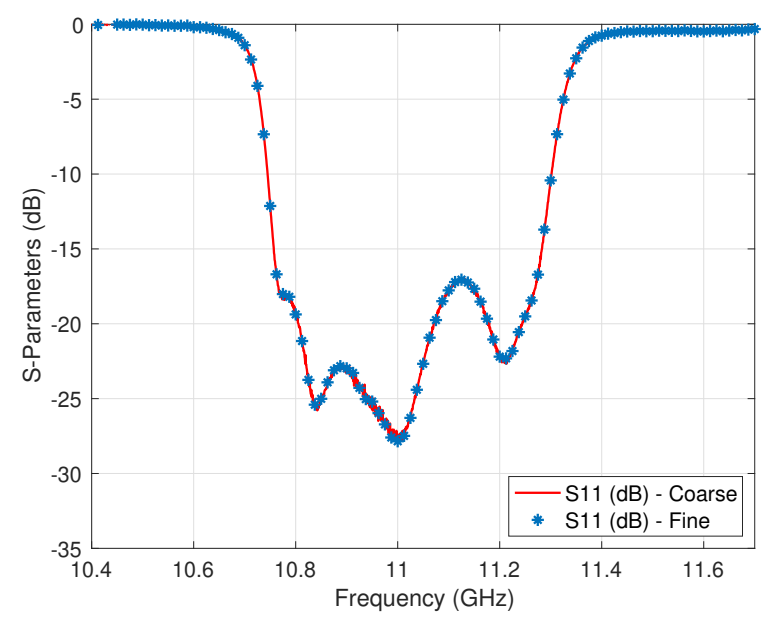

Fig. 14. Procedure V: the starting point where the mapping is computed.

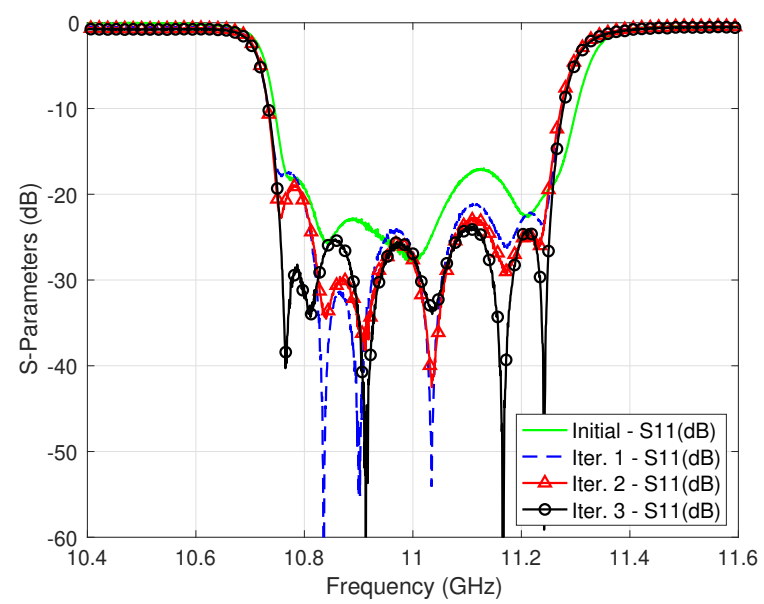

Fig. 15. Tuning procedure V using $\mathbf{B}$ computed directly with Filter $\mathbf{1}$.

\section{General Guidelines to Choose a Tuning METHOD}

Throughout this paper, five tuning methods have been discussed. This section aims to clarify their pros and cons. Table XI summarizes the key features of each method:

- Time: Simulation time necessary to tune each filter.

- Extra: Time needed to modify the positions of the tuners with Robby. In our experience, the average time needed to modify all tuners is 3 minutes. The extra time is computed as $N I \cdot 3$ minutes. In the case of Procedure $\mathrm{V}$, the extra time is computed as $(N I+1) \cdot 3$ minutes since the estimation of $\mathbf{B}$ is also performed with Robby.

- Time*: Time + Extra. This is the overall time needed to tune the filter.

- Initial State Refinement (ISR): This is a Yes/No (Y/N) metric that indicates whether an initial manual adjustment is required to guarantee the convergence of the procedure.

Procedure I is clearly the worst method. As it was stated at the beginning of the paper, it is only used as a reference for the evaluation of the efficiency of all other tuning procedures. Procedure II is considerably faster than Procedure I and we would always prefer this method. Procedures III and IV are improved versions of Procedure II that rely on the use of an efficient full-wave simulator as FEST3D. In case such tool is available, we would always choose Procedure IV. Even though Procedure V seems to be the fastest method, that may not always be the case. In this procedure, an Initial State Refinement is necessary, and the time needed depends on the complexity of the filter and the experience of the engineer tuning the filter.

Advantages of Procedure IV over Procedure V:

- Procedure IV does not require any previous filter tuning experience since no Initial State Refinement is needed.

- It is likely to be the fastest tuning method, since the Initial State Refinement of a complex filter is likely to take more than 3 minutes.

Disadvantages of Procedure IV over Procedure V:

- Procedure IV requires the use of a full-wave simulation tool that can efficiently model the tuning elements.

We can now provide some guidelines to choose the best tuning method. As a general rule of thumb:

- IF the EM tools necessary to perform Procedure IV are available: use Procedure IV.

- ELSE:

- IF the complexity of the filter allows for a quick manual adjustment that improves the filter response: apply Procedure V.

- ELSE: Use Procedure II with a reduced optimization space.

\section{CONClusion}

The objective of this investigation was to provide a simple and effective solution to the complex problem of microwave filter tuning. In order to do so, a SM-based technique was developed and validated by tuning a 6-pole inductive waveguide filter. An enhancement of this method was then developed to speed up the process. In the second version of the method, the high precision structure was replaced by a low precision simulator. By combining this new approach with a reduced optimization space, the same filter was tuned considerably faster. Finally, we showed how the mapping can be evaluated directly using the real hardware being tuned, the VNA and any coarse model that is available.

This contribution is, in our opinion, of great practical value for all professionals involved in the industrial tuning of microwave filters. The procedures described can be successfully used even without the availability of sophisticated full-wave EM simulation tools. Finally, it is important to note that even though our investigation uses a six-pole inductive filter in rectangular waveguide, the tuning procedures described in this paper are also fully applicable to any microwave filter that includes tuning elements.

\section{REFERENCES}

[1] J. B. Ness and V. A. Lenivenko, "Design and manufacture of 'exact' waveguide filters," in Proc. Asia-Pacific Microw. Conf., Dec. 2000, pp. 507-511. 
TABLE XI

COMPARISON OF THE DIFFERENT TUNING METHODS.

\begin{tabular}{|c|c|c|c|c|c|}
\hline Procedure & I & II & III & IV & V \\
\hline Time & $6 \mathrm{~h} 10 \mathrm{~min} 50 \mathrm{~s}$ & $1 \mathrm{~h} 5 \mathrm{~s}$ & $13 \min 34 \mathrm{~s}$ & $8 \min 52 \mathrm{~s}$ & $5 \min 35 \mathrm{~s}$ \\
\hline Extra & $12 \mathrm{~min}$ & $12 \mathrm{~min}$ & $15 \min$ & $12 \mathrm{~min}$ & $12 \mathrm{~min}$ \\
\hline Time* $^{*}$ & $6 \mathrm{~h} 22 \mathrm{~min} 50 \mathrm{~s}$ & $1 \mathrm{~h} 12 \min 5 \mathrm{~s}$ & $28 \min 34 \mathrm{~s}$ & $20 \min 52 \mathrm{~s}$ & $17 \min 35 \mathrm{~s}$ \\
\hline ISR & $\mathrm{N}$ & $\mathrm{N}$ & $\mathrm{N}$ & $\mathrm{N}$ & $\mathrm{Y}$ \\
\hline
\end{tabular}

[2] R. J. Cameron, C. M. Kudsia, and R. R. Mansour, Microwave Filters for Communication Systems: Fundamentals, Design and Applications. NJ: John Wiley \& Sons, 2018.

[3] V. Boria, M. Guglielmi, and P. Arcioni, "Accurate CAD for dual mode filters in circular waveguide including tuning elements," in IEEE MTT-S Int. Microw. Symp. Dig., vol. 3, Jun. 1997, pp. 1575-1578.

[4] R. V. Snyder, "Practical aspects of microwave filter development," IEEE Microw. Mag., vol. 8, no. 2, pp. 42-54, Apr. 2007.

[5] A. Lindner and E. Biebl, "A manual tuning method for coupled cavity filters," in Proc. 36th Eur. Microw. Conf., Sep. 2006, pp. 1340-1342.

[6] L. Accatino, "Computer-aided tuning of microwave filters," in IEEE MTT-S Int. Microw. Symp. Dig., Jun. 1986, pp. 249-252.

[7] A. R. Mirzai, C. F. N. Cowan, and T. M. Crawford, "Intelligent alignment of waveguide filters using a machine learning approach," IEEE Trans. Microw. Theory Techn., vol. 37, no. 1, pp. 166-173, Jan. 1989.

[8] J. Zhou and J. Huang, "Intelligent tuning for microwave filters based on multi-kernel machine learning model," in Proc. 5th IEEE Int. Symp. Microw. Ant. Prop. EMC Tech. Wir. Comm., Oct. 2013, pp. 259-266.

[9] V. Miraftab and R. R. Mansour, "Computer-aided tuning of microwave filters using fuzzy logic," IEEE Trans. Microw. Theory Techn., vol. 50, no. 12, pp. 2781-2788, Dec. 2002.

[10] V. Miraftab and R. R. Mansour, "Automated microwave filter tuning by extracting human experience in terms of linguistic rules using fuzzy controllers," in IEEE MTT-S Int. Microw. Symp. Dig., Jun. 2006, pp. 1439-1442.

[11] N. Zahirovic, R. R. Mansour, and M. Yu, "Scalar measurement-based algorithm for automated filter tuning of integrated chebyshev tunable filters," IEEE Trans. Microw. Theory Techn., vol. 58, no. 12, pp. 37493759, Dec. 2010.

[12] D. Miek and M. Höft, "Compensation of cross-dependencies in computer aided tuning of microwave filters by simplified space mapping approach," in Proc. IEEE MTT-S Int. Conf. Numer. Electromagn. Multiphys. Modeling Optim., Aug. 2018, pp. 1-4.

[13] J. W. Bandler, R. M. Biernacki, S. H. Chen, P. A. Grobelny, and R. H. Hemmers, "Space mapping technique for electromagnetic optimization," IEEE Trans. Microw. Theory Techn., vol. 42, no. 12, pp. 2536-2544, Dec. 1994.

[14] J. W. Bandler, R. M. Biernacki, S. H. Chen, R. H. Hemmers, and K. Madsen, "Electromagnetic optimization exploiting aggressive space mapping," IEEE Trans. Microw. Theory Techn., vol. 43, no. 12, pp. 2874-2882, Dec. 1995.

[15] J. W. Bandler, R. M. Biernacki, S. H. Chen, and D. Omeragic, "Space mapping optimization of waveguide filters using finite element and mode-matching electromagnetic simulators," in IEEE MTT-S Int. Microw. Symp. Dig., vol. 2, Jun. 1997, pp. 635-638.

[16] M. A. Ismail, D. Smith, A. Panariello, Y. Wang, and M. Yu, "EMbased design of large-scale dielectric-resonator filters and multiplexers by space mapping," IEEE Trans. Microw. Theory Techn., vol. 52, no. 1, pp. 386-392, Jan. 2004.

[17] Q. Shi and M. Yu, "Ka-band dual multiplexer with a connected channel," in IEEE MTT-S Int. Microw. Symp. Dig., Jun. 2013, pp. 1-3.

[18] M. A. Ismail and M. Yu, "Advanced design of large scale microwave devices for space applications using space mapping optimization," in IEEE MTT-S Int. Microw. Symp. Dig., Jun. 2017, pp. 1515-1516.

[19] S. Li and P. D. Laforge, "A post-fabrication tuning method for a varactortuned microstrip filter using the implicit space mapping technique," in IEEE MTT-S Int. Microw. Symp. Dig., May 2015, pp. 1-4.

[20] A. Rodriguez, J. V. Morro, J. Selga, M. Sans, J. Ossorio, M. Guglielmi, F. Martín, and V. E. Boria, "Robust optimization and tuning of microwave filters and artificial transmission lines using aggressive space mapping techniques," in IEEE MTT-S Int. Microw. Symp. Dig., Jun. 2017, pp. 1501-1504

[21] M. Brumos, V. E. Boria, M. Guglielmi, and S. Cogollos, "Correction of manufacturing deviations in circular-waveguide dual-mode filters using aggressive space mapping," in Proc. 44th Eur. Microw. Conf., Oct. 2014, pp. 624-627.

[22] S. Li, X. Fan, P. D. Laforge, and Q. S. Cheng, "Space mapping postfabrication tuning of 3D printed air-filled waveguide filter," in IEEE MTT-S Int. Microw. Symp. Dig., Jun. 2017, pp. 1635-1637.

[23] J. Melgarejo, M. Guglielmi, S. Cogollos, and V. E. Boria, "Space mapping for tuning waveguide microwave filters," in IEEE MTT-S Int. Microw. Symp. Dig., Jun. 2019.

[24] J. Ossorio, J. C. Melgarejo, V. E. Boria, M. Guglielmi, and J. W. Bandler, "On the alignment of low-fidelity and high-fidelity simulation spaces for the design of microwave waveguide filters," IEEE Trans. Microw. Theory Techn., vol. 66, no. 12, pp. 5183-5196, Dec. 2018.

[25] J. Ossorio, J. Vague, V. E. Boria, and M. Guglielmi, "Efficient implementation of the aggressive space mapping technique for microwave filter design," in Proc. 47th Eur. Microw. Conf., Oct. 2017, pp. 644-647.

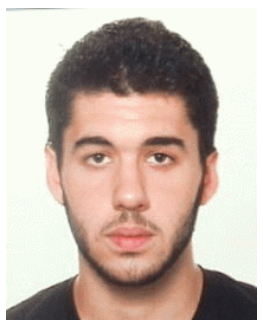

Juan Carlos Melgarejo was born in Alicante, Spain in 1993. He obtained his bachelor's degree in Telecommunications from the Universitat Politècnica de València (UPV) in 2015. From there, he continued his studies with the UPV where he pursued a double Master's in Telecommunications Systems. In 2017, he began his Ph.D. at the university where his main research interests have been investigating microwave passive devices and new manufacturing techniques for satellite components.

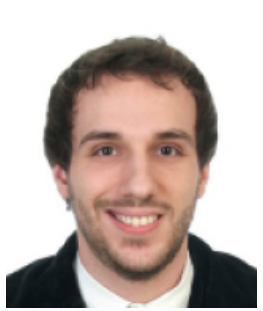

Javier Ossorio was born in Valencia, Spain, on March 24, 1992. He received the degree and double master in telecommunications engineering from the Polytechnic University of Valencia, Spain, in 2014 and 2016, respectively. He is currently a Ph.D student in telecommunications in the iTEAM group at Polytechnic University of Valencia. His current research activities includes EM simulations, efficient design and optimizations of waveguide filters and development of new tunable structure filters for satellite applications. 


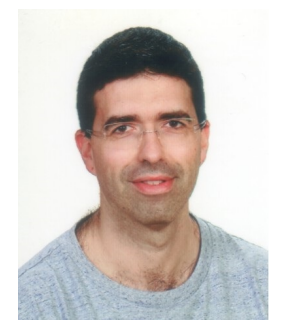

Santiago Cogollos was born in Valencia, Spain, on January 15,1972 . He received the degree in telecommunication engineering and the $\mathrm{Ph}$. D. degree from the Universitat Politècnica de València (UPV), Valencia, Spain, in 1996 and 2002, respectively. In 2000 he joined the Communications Department of the Universitat Politècnica de València, where he was an Assistant Lecturer from 2000 to 2001, a Lecturer from 2001 to 2002, and became an Associate Professor in 2002. He has collaborated with the European Space Research and Technology Centre of the European Space Agency in the development of modal analysis tools for payload systems in satellites. In 2005 he held a post doctoral research position working in the area of new synthesis techniques in filter design at University of Waterloo, Waterloo, Ont., Canada. His current research interests include applied electromagnetics, mathematical methods for electromagnetic theory, analytical and numerical methods for the analysis of microwave structures, and design of waveguide components for space applications.

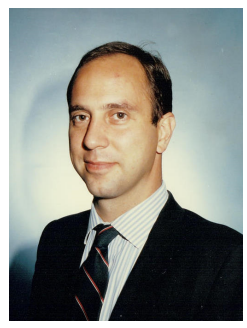

Marco Guglielmi was born in Rome, Italy, on December 17, 1954. He received the degree "Laurea in Ingegneria Elettronica" in 1979 from the University of Rome "La Sapienza", Rome, Italy, where in 1980 he also attended the "Scuola di Specializzazione in Elettromagnetismo Applicato". In 1981 he was awarded a Fulbright Scholarship in Rome, Italy, and an HISP (Halsey International Scholarship Programme) from the University of Bridgeport, Bridgeport, Connecticut, USA, where in 1982 he obtained an MS Degree in Electrical Engineering. In 1986 he received a $\mathrm{PhD}$ degree in Electrophysics from the Polytechnic University, Brooklyn, New York, USA. From 1984 to 1986 he was Academic Associate at Polytechnic University, and from 1986 to 1988 he was Assistant Professor in the same institution. From 1988 to 1989 he was Assistant Professor at the New Jersey Institute of Technology, Newark, New Jersey, USA. In 1989 he joined the European Space Agency as a Senior Microwave Engineer in the RF System Division of the European Space Research and Technology Centre (ESTEC), Noordwijk, The Netherlands, where he was in charge of the development of microwave filters and electromagnetic simulation tools. In 2001 he was appointed Head of the Technology Strategy Section of ESTEC where he contributed to the development of management processes and tools for the formulation of a European strategy for Space Technology Research and Development. In 2014 Dr. Guglielmi retired from the European Space Agency and is currently holding the position of Invited Senior Researcher at the Polytechnic University of Valencia, Valencia, Spain. Dr. Guglielmi has been elevated to the grade of Fellow of the IEEE in January 2013 "For contributions to multimode equivalent networks and microwave filter design".

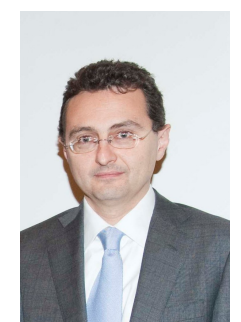

Vicente E. Boria (S'91-A'99-SM'02-F'18) was born in Valencia, Spain, on May 18, 1970. He received his "Ingeniero de Telecomunicación" degree (with first-class honors) and the "Doctor Ingeniero de Telecomunicación" degree from the Universidad Politécnica de Valencia, Valencia, Spain, in 1993 and 1997, respectively. In 1993 he joined the "Departamento de Comunicaciones", Universidad Politécnica de Valencia, where he has been Full Professor since 2003. In 1995 and 1996, he was holding a Spanish Trainee position with the European Space Research and Technology Centre, European Space Agency (ESTEC-ESA), Noordwijk, The Netherlands, where he was involved in the area of EM analysis and design of passive waveguide devices. He has authored or co-authored 10 chapters in technical textbooks, 180 papers in refereed international technical journals, and over 200 papers in international conference proceedings. His current research interests are focused on the analysis and automated design of passive components, left-handed and periodic structures, as well as on the simulation and measurement of power effects in passive waveguide systems. Dr. Boria has been a member of the IEEE Microwave Theory and Techniques Society (IEEE MTT-S) and the IEEE Antennas and Propagation Society (IEEE AP-S) since 1992. He is also member of the European Microwave Association (EuMA), and has been the Chair of the 48th European Microwave Conference held in Madrid, Spain. He acts as a regular reviewer of the most relevant IEEE and IET technical journals on his areas of interest. He has been Associate Editor of IEEE Microwave and Wireless Components Letters (2013-2018) and IET Electronics Letters (2015-2018). Presently, he serves as Subject Editor (Microwaves) of IET Electronics Letters, and as Editorial Board member of International Journal of RF and Microwave Computer-Aided Engineering. He is also member of the Technical Committees of the IEEE-MTT International Microwave Symposium and of the European Microwave Conference.

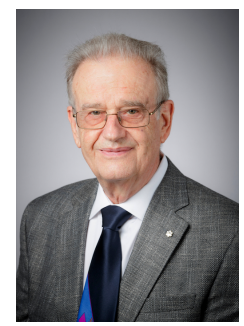

John W. Bandler (S'66-M'66-SM'74-F'78-LF'06) studied at Imperial College, London, England, and received the B.Sc.(Eng.), Ph.D., and D.Sc.(Eng.) degrees from the University of London, England, in 1963, 1967, and 1976, respectively. He joined McMaster University, Canada, in 1969. He is now a Professor Emeritus. He founded Optimization Systems Associates Inc. in 1983 and sold it to HewlettPackard in 1997. He is President of Bandler Corporation, Dundas, Ontario, Canada. Dr. Bandler is a Fellow of several societies, including the Royal Society of Canada and the Canadian Academy of Engineering. In 2004, he received the IEEE MTT-S Microwave Application Award. In 2012, he received the IEEE Canada McNaughton Gold Medal and the Queen Elizabeth II Diamond Jubilee Medal. In 2013, he received the IEEE MTT-S Microwave Career Award. In 2014, he received McMaster University's Faculty of Engineering Research Achievement Award. In 2016 he was honored by appointment to Officer of the Order of Canada. In 2018, Professional Engineers Ontario awarded him their Gold Medal. Dr. Bandler pioneered space mapping in 1993. 